\title{
The zombie theory of genetic intelligence
}

\author{
Terry Wrigley
}

ABSTRACT The notion that 'intelligence' or 'ability' is genetically inherited refuses to die. This article reviews the way such a notion has long been used to justify inequality in society, and considers the methodological failings and deceptions, and the interpretative blind-spots, of those who advance the heritability of 'intelligence' as a basis for understanding people's learning.

The idea that academic ability is fixed and innate has damaged generations of children. Intelligence tests were used across Britain from the 1920s to 1970s to separate children from age 11, and still are in some parts of England. On this basis, most manual workers' children were consigned to poorly funded schools, and left a few years later without qualifications. These tests supposedly measured an innate intelligence unaffected by schooling, yet children were made to practise day after day to raise their scores. It was assumed that a few children from manual-worker families had somehow acquired a surprisingly good set of genes and should be educated in grammar schools, but the vast majority should receive a short, cheap and low-quality education in secondary modern schools.

The belief that academic ability is genetically inherited has long served to justify inequality. The tendency for children from prosperous families to score higher on IQ tests was used to justify these families' wealth. As Henry Goddard, a founding father of IQ theory in the USA, put it: "The people who are doing the drudgery are, as a rule, in their proper places" (Goddard 1919). He explained to students at Princeton in 1919: "Now the fact is, that workmen may have a ten year intelligence while you have a twenty. How can there be such a thing as a social equality with this wide range of mental capacity?" (cited in Gould 1996:191) Cyril Burt, the most influential proponent of genetic IQ theory in England, began his research career by testing the sons of Oxford academics and the sons of skilled manual workers. He regarded the higher scores of the academics' children as proof that intelligence was genetic, disregarding any possible effects of upbringing, family culture, or the different schools they attended. The assumption that the higher scores of the children of richer and better educated parents are due to genetic rather than environmental factors exemplifies an elite's ideological attempt to justify its own wealth and privilege. It also connects with an imperialist ideology of British racial superiority, a fear that the "British race" would degenerate if the poor had too many children. Even in his undergraduate notebook, Burt had written:

The problem of the very poor - chronic poverty; little prospect of the solution of the problem without the forcible detention of the wreckage of society or otherwise preventing them from propagating their own species. (quoted in Rose et al 1984:87)

More recently Michael Gove's special adviser Dominic Cummings (and subsequently campaign director for Vote Leave) wrote a paper proposing that the most gifted 1 in 10,000 children should be identified, segregated and trained to rule the world (Cummings 2013). He even presented a reading list for these supermen and (maybe) superwomen: advanced mathematics and modern physics, genetic theories of IQ, a few books about economics, military strategy and (of course) leadership. 
Burt's ultimate proof of genetic intelligence was his studies of separated identical twins who had been adopted. This was finally shown to be a fraud after his death. Because this fitted the dominant ideology of the period, no one had questioned the lack of detail about the samples, the IQ test administered, and so on. Finally someone smelt a rat: in three separate studies, with three different sets of adopted pairs of twins, the correlation was identical to three decimal points - a highly implausible result. It was finally realised that the research had never actually happened (Rose et al 1984:103seq).

Later twins studies are seriously problematic. In a major Swedish study, it turned out that most of the 'separated' twins had not lived separate lives; indeed in half the cases one stayed with mum while the other lived nearby with granny or an aunt.

The most famous and longlasting twins study, in the USA, was the Minnesota Study of Twins Reared Apart (MISTRA, led by Thomas Bouchard). It relied on self-selection - pairs of twins coming forward because they believed they were very similar. For obvious reasons, a study based on volunteer twins recruited through media appeals will produce a sample weighted to pairs of twins who are behaviourally similar. It began, with a blaze of publicity, with two twins named Jim by their adoptive parents. Both had married and divorced a woman called Linda, remarried a Betty, and had a dog called Toy. They had both been firemen, and went for holidays to the same beach, but claimed never to have met till age 39. Are we supposed to believe in a gene for marrying women called Linda and Betty, or is somebody having a laugh? Perhaps some of its advocates have inherited a gullibility gene? (See Joseph 2001 for a detailed critique; also Jay Joseph's blog www.madinamerica.com for other studies.)

\section{Flawed methodology}

The studies rely on several shaky premises. Fundamentally the hypothesis is that intelligent thinking in different fields is underpinned by an innate generic intelligence (known as ' $\mathrm{g}$ '). Since researchers within this paradigm restrict 'intelligence' to abstract forms of problem-solving, whether verbal or mathematical, it is not surprising that these skills correlate with one another; even so, the various sub-tests in use do not correlate well. This overlap is assumed to be the generic innate core; an easier explanation is that the tasks involve overlapping skills. There is also a deep flaw in the claim that the abstract questions found in IQ tests identify 'innate intelligence' independent of school-based learning.

Even when two identical twins are genuinely separated, they do not have randomly different environments. They are the same sex, born on the same day, attend schools run along similar lines. They grow up in the same culture, including current fashions and trends in music. Vetting procedures for adoption ensure that prospective parents are reasonably well off, quite well educated, and are likely to be very caring parents. All of this weights the statistics by reducing environmental variability, thus making heritability appear larger. The problem with the mathematical method, and the concept of hereditability, can best be understood by analogy. Imagine a country where every child enjoys perfect nutrition and exercise and most of them grow to nearly 2 metres tall. Because nobody's growth is restricted by upbringing, the differences in their heights will be entirely genetic. 'Heritability' will calculate as $100 \%$ and, in this perfect environment, environmental 
effects will count as zero! In reality of course, environment will have made a major contribution to their growth.

Tim Morris (2013) provides some excellent examples of this paradox. For example, the heridability of hair colour in a Chinese population is quite low, but quite high among Australians. This is not because genetics has a greater influence in Australia - simply that there is little variation in hair colour among the Chinese. Calculations which showed hereditability for height of $80 \%$ would not mean we could break down a person's height into four-fifths due to genetics and one-fifth of environmentally caused growth.

IQ scores were meant to be fixed throughout life, because they measured inherited intelligence. This assumption is contradicted by the fact that they have risen dramatically in entire populations - known as the Flynn Effect. James Flynn has assembled data from many different countries to show an IQ gain of around 15 points each generation (one Standard Deviation), as society changes and education improves. In other words, someone who now scores as average would have appeared extremely bright if tested 30 years earlier. Consequently, test designers periodically recalibrate test scores.

The notion that genes can tightly determine behaviour is also contradicted by recent scientific understanding known as epigenetics. Genes interact in complex ways, they are switched on and off, their impact is modified by a kind of dimmer switch, and environmental issues such as stress or poor nutrition can have a long-term impact on how genes have an effect.

\section{The revival of genetic intelligence in the UK}

Now behavioural geneticists argue that it isn't a single gene but probably hundreds, each with a tiny effect. In one of the largest studies of the human genome to date (Lee et al 2018; see also https://www.thessgac.org/faqs), a group of 253 scientists from around the world identified 74 genetic variants that were linked with the number of years spent in formal education. But the researchers found that the largest effect of any one genetic variant was just 0.035 per cent. Even the combined effect of the 74 genetic variants on educational attainment was only 0.43 per cent! Despite the vast amounts spent, genetics researchers haven't even been able to find a gene for height: the genetic variant with the largest assocation predicts just $0.4 \%$ of the variation between individuals.

A team led by John Jerrim (Jerrim et al 2015) looked into the claim that there is a gene for literacy. This was supposed to explain why reading success was more common in advantaged families. There were supposedly two for reading success and one for reading disorders, but Jerrim's team found very low impact. They concluded that "these genetic factors can account for just 2-3\% of the socio-economic achievement gap".

The leading IQ researcher now in the UK is Robert Plomin, whose early career was with the US twins study. His more recent studies compare identical twins with non-identical twins and other siblings, with no requirement of separation i.e. normally living in the same home. In 2013 a study by his team concluded that there was an heritability of 58\% for GCSE grades in English, maths and science. Yet in interviews he has fully recognised the mathematical paradox: that a shared environment will raise the 'heritability' score. These twins not only grew up in the same family but attended the same schools, and were often taught by the same 
teachers. Calculations in this study are based on the 'equal environments' myth: i.e. that all siblings living with their parents have identical experiences, and that identical twins are no different in their experiences than other brothers and sisters. This is dubious since identical twins are often persuaded into dressing the same and doing things together. They are likely to be in the same class, have the same maths teachers, work together on homework and so on.

Conversely, children in different families brought up in the same culture and educated in the same school system do not have a radically different environment. Despite levels of poverty and social division, children growing up at the same time in our society have much of their environments in common - the same National Curriculum, similar assumptions in the way schools are run, shared musical fashions, and so on.

Based on this spurious premise that 'equal environments' applies as much to identical twins as to all siblings, but with a different environment for other families, Plomin's study calculates how much GCSE results derive from innate ability, and how little from environment and experience. It fails to look directly at parents' qualification or income and how that correlates with the GCSE grades.

A recent British study led by Tim Morris (Morris et al 2018) calculates the hereditability of GCSE results (calculated in points) as $61 \%$. This should be read against the earlier explanation that hereditability scores rise as the environment becomes more uniform. Hereditability scores are higher in places (like the UK) where there is a great stress on school learning, a universal entitlement and a largely uniform educational system. In other words, it is not a measure of the power of genes to affect intelligence. Actually the study doesn't measure something we might call 'intelligence' at all; it simply measures attainment differences. The method is based not on twins, but on investigating links between the variation in GCSE scores and the genetic variation in a large population. In other words, do students with similar scores have greater genetic similarity than one might expect. It is important not to assume that the genetic similarities are a measure of intelligence; they will include all kinds of physical and personality differences which impact on attainment. The greater genetic similarity may also result from obscure factors such as a tendency over several generations for people with similar levels of education to marry endogeneously (in other words, for Oxbridge graduates to tend to marry other Oxbridge graduates).

It is impossible to conclude from such studies the degree to which academic achievement results from genetic make-up, or to apportion between genes and environment. It is even impossible to deduce that there is a unitary quality that we might call 'general intelligence'. The data takes us no nearer understanding the causes of school attainment. To do so would require finding the causal mechanism. As shown earlier, the largest GWAS (genome-wide association study) has only managed to identify genetic variants which, in combination, account for less than half a percent of the variation in educational attainment.

\section{And yet...}

Despite the shakiness of this research paradigm, and over half a century since Burt's twins studies were exposed, the school system acts as if intelligence were something fixed. The planned reintroduction of baseline tests for four year olds tacitly assumes, despite all the evidence, that children's ability and potential 
are fixed quantities. Children continue to be sorted into 'ability groups' soon after starting school, and taught separately on different tables, without stopping to think what is meant by 'ability'. The notion of genetic intelligence has survived like a zombie in discriminatory practices of ranking and segregating.

\section{References}

Cummings, D (2013) Some thoughts on education and political priorities. https://static.guim.co.uk/ni/1381763590219/-Some-thoughts-on-education.pdf

Goddard, H (1919) Psychology of the normal and subnormal. New York: Dodd and Mead.

Gould, S (1996) The mismeasure of man. New York: W.W.Norton

Jerrim, J, Vignoles, A, Lingam, R and Friend, A (2015) The socio-economic gradient in children's reading skills and the role of genetics. British Educational Research Journal 41(1):6-29

Joseph, J (2001) Separated twins and the genetics of personality differences: A critique. The American Journal of Psychology 114(1):1-30

Lee, J et al (2018) 'Gene discovery and polygenic prediction from a 1.1 million person GWAS of educational attainment" Nature Genetics https://scholar.harvard.edu/files/laibson/files/ssgac_naturegenetics_072318.pdf

Morris, T, Davies, N, Dorling, D, Richmond, R and Smith, G(2018) Testing the validity of value-added measured of educational progress with genetic data. British Educational Research Journal 44(5):725-747

Morris, T (2013) Explainer: What is hereditability? https://theconversation.com/explainer-what-isheritability-21334

Rose, S, Lewontin, R and Kamin, L (1984) Not in our genes: Biology, ideology and human nature. London: Penguin 